\title{
Hot branching dynamics in a lightharvesting iron carbene complex revealed by ultrafast xray emission spectroscopy
}

Tatsuno, Hideyuki; Kjær, Kasper Skov; Kunnus, Kristjan; Harlang, Tobias C. B.; Timm, Cornelia; Guo, Meiyuan; Chabera, Pavel; Fredin, Lisa A.; Hartsock, Robert W.; Reinhard, Marco E.

Total number of authors:

42

Published in:

Angewandte Chemie

Link to article, DOI:

10.1002/ange.201908065

Publication date:

2020

Document Version

Peer reviewed version

Link back to DTU Orbit

Citation (APA):

Tatsuno, H., Kjær, K. S., Kunnus, K., Harlang, T. C. B., Timm, C., Guo, M., Chabera, P., Fredin, L. A., Hartsock, R. W., Reinhard, M. E., Koroidov, S., Li, L., Cordones, A., Gordivska, O., Prakash, O., Liu, Y., Laursen, M., Biasin, E., Hansen, F. B. K., ... Uhlig, J. (2020). Hot branching dynamics in a lightharvesting iron carbene complex revealed by ultrafast xray emission spectroscopy. Angewandte Chemie, 132(1), 372-380.

https://doi.org/10.1002/ange.201908065

\section{General rights}

Copyright and moral rights for the publications made accessible in the public portal are retained by the authors and/or other copyright owners and it is a condition of accessing publications that users recognise and abide by the legal requirements associated with these rights.

- Users may download and print one copy of any publication from the public portal for the purpose of private study or research.

- You may not further distribute the material or use it for any profit-making activity or commercial gain

- You may freely distribute the URL identifying the publication in the public portal 


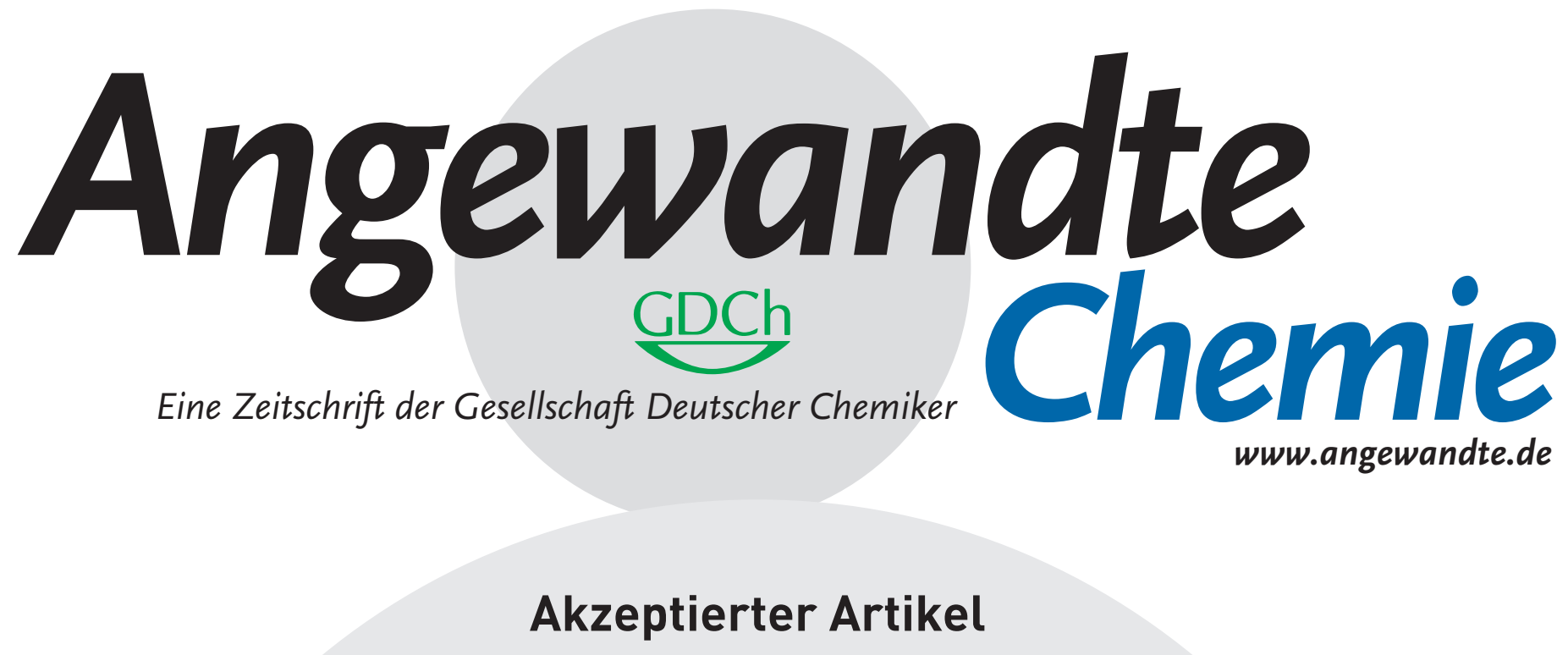

Titel: Hot branching dynamics in a light-harvesting iron carbene complex revealed by ultrafast x-ray emission spectroscopy

Autoren: Hideyuki Tatsuno, Kasper S. Kjaer, Kristjan Kunnus, Tobias Harlang, Cornelia Timm, Meiyuan Guo, Pavel Chabera, Lisa Fredin, Robert Hartsock, Marco Reinhard, Sergey Koroidov, Lin Li, Amy Cordones, Olga Gordivska, Om Prakash, Yizhu Liu, Mads Laursen, Elisa Biasin, Frederik B. Hansen, Peter Vester, Morten Christensen, Kristoffer Haldrup, Zoltán Németh, Dorottya Sárosiné Szemes, Éva Bajnóczi, György Vankó, Tim van Driel, Roberto Alonso-Mori, James Glownia, Silke Nelson, Marcin Sikorski, Henrik Lemke, Dimosthenis Sokaras, Sophie E. Canton, Asmus Ougaard Dohn, Klaus Braagaard Møller, Martin M. Nielsen, Kelly J. Gaffney, Kenneth Wärnmark, Villy Sundström, Petter Persson, and Jens Uhlig

Dieser Beitrag wurde nach Begutachtung und Überarbeitung sofort als "akzeptierter Artikel" (Accepted Article; AA) publiziert und kann unter Angabe der unten stehenden Digitalobjekt-Identifizierungsnummer (DOI) zitiert werden. Die deutsche Übersetzung wird gemeinsam mit der endgültigen englischen Fassung erscheinen. Die endgültige englische Fassung (Version of Record) wird ehestmöglich nach dem Redigieren und einem Korrekturgang als Early-View-Beitrag erscheinen und kann sich naturgemäß von der AA-Fassung unterscheiden. Leser sollten daher die endgültige Fassung, sobald sie veröffentlicht ist, verwenden. Für die AA-Fassung trägt der Autor die alleinige Verantwortung.

Zitierweise: Angew. Chem. Int. Ed. 10.1002/anie.201908065 Angew. Chem. 10.1002/ange.201908065

Link zur VoR: http://dx.doi.org/10.1002/anie.201908065 http://dx.doi.org/10.1002/ange.201908065 


\title{
Hot branching dynamics in a light-harvesting iron carbene complex revealed by ultrafast x-ray emission spectroscopy
}

Hideyuki Tatsuno $^{1}$, Kasper S. Kjær ${ }^{1,2}$, Kristjan Kunnus ${ }^{3}$, Tobias C. B. Harlang ${ }^{1}$, Cornelia Timm ${ }^{1}$, Meiyuan Guo ${ }^{1}$, Pavel Chàbera ${ }^{1}$, Lisa A. Fredin ${ }^{2}$, Robert W. Hartsock ${ }^{3}$, Marco E. Reinhard ${ }^{3}$, Sergey Koroidov $^{3}$, Lin Li ${ }^{3}$, Amy A. Cordones ${ }^{3}$, Olga Gordivska ${ }^{4}$, Om Prakash ${ }^{4}$, Yizhu Liu ${ }^{1,4}$, Mads G. Laursen $^{5}$, Elisa Biasin ${ }^{5}$, Frederik B. Hansen ${ }^{5}$, Peter Vester ${ }^{5}$, Morten Christensen ${ }^{5}$, Kristoffer Haldrup ${ }^{5}$, Zoltán Németh ${ }^{6}$, Dorottya Sárosiné Szemes ${ }^{6}$, Éva Bajnóczi ${ }^{6}$, György Vankó ${ }^{6}$, Tim B. Van

Driel $^{8}$, Roberto Alonso-Mori ${ }^{8}$, James M. Glownia ${ }^{8}$, Silke Nelson ${ }^{8}$, Marcin Sikorski ${ }^{8}$, Henrik T. Lemke $^{8,9}$, Dimosthenis Sokaras ${ }^{10}$, Sophie E. Canton ${ }^{11,12}$, Asmus O. Dohn ${ }^{13,14}$, Klaus B. Møller ${ }^{13}$, Martin M. Nielsen ${ }^{5}$, Kelly Gaffney ${ }^{3}$, Kenneth Wärnmark ${ }^{4}$, Villy Sundström ${ }^{1}$, Petter Persson ${ }^{2}$, and Jens Uhlig ${ }^{1, *}$

${ }^{1}$ Division of Chemical Physics, Department of Chemistry, Lund University, Box 124, Lund SE-22100, Sweden

${ }^{2}$ Theoretical Chemistry Division, Department of Chemistry, Lund University, Box 124, Lund SE-22100, Sweden

${ }^{3}$ PULSE Institute, SLAC National Accelerator Laboratory, Stanford University, Menlo Park, California 94025, United States

${ }^{4}$ Centre for Analysis and Synthesis, Department of Chemistry, Lund University, Box 124, Lund SE-22100, Sweden

${ }^{5}$ Department of Physics, Technical University of Denmark, DK-2800, Lyngby, Denmark

${ }^{6}$ Wigner Research Centre for Physics, Hungarian Academy of Sciences, P.O. Box 49, H-1525 Budapest, Hungary

${ }^{8}$ LCLS, SLAC National Accelerator Laboratory, Menlo Park, California 94025, United States ${ }^{9}$ SwissFEL, Paul Scherrer Institut, Villigen PSI 5232, Switzerland

${ }^{10}$ SSRL, SLAC National Accelerator Laboratory, Menlo Park, California 94025, United States ${ }^{12}$ ELI-ALPS, ELI-HU Non-Profit Ltd., Dugonics ter 13, Szeged 6720, Hungary

${ }^{11}$ FS-ATTO, Deutsches Elektronen-Synchrotron (DESY), Notkestrasse 85, D-22607 Hamburg, Germany

${ }^{13}$ Department of Chemistry, Technical University of Denmark, DK-2800, Lyngby, Denmark

${ }^{14}$ Faculty of Physical Sciences and Science Institute, University of Iceland, 107 Reykjavik, Iceland *corresponding author:jens.uhlig@chemphys.lu.se

\begin{abstract}
Iron nitrogen heterocyclic carbenes (NHC) have received a great deal of attention recently, due to their growing potential as e.g light sensitizers and photocatalysts. We present a sub-ps x-ray spectroscopy study of a $\mathrm{Fe}^{\mathrm{II}} \mathrm{NHC}$ complex allowing us to identify and quantify the states involved in the deactivation cascade after light absorption. We find that excited molecules relax back to the ground state along two pathways: after population of a hot ${ }^{3} \mathrm{MLCT}$ state, from the initially excited ${ }^{1}$ MLCT state, $\sim 30 \%$ of the molecules undergo ultrafast ( $150 \mathrm{fs}$ ) relaxation to the ${ }^{3} \mathrm{MC}$ state, in competition with vibrational relaxation and cooling to the relaxed ${ }^{3} \mathrm{MLCT}$ state. The relaxed ${ }^{3} \mathrm{MLCT}$ state then decays much more slowly (7.6 ps) to the ${ }^{3} \mathrm{MC}$ state. The ${ }^{3} \mathrm{MC}$ state is rapidly $(2.2 \mathrm{ps})$ deactivated to the ground state. The ${ }^{5} \mathrm{MC}$ state is not involved in the deactivation pathway. The ultrafast partial deactivation of the ${ }^{3}$ MLCT state constitutes a loss channel from the point of view of photochemical efficiency and highlights the necessity to screen other FeNHC complexes (and perhaps other transition metal complexes) for this ultrafast decay of ${ }^{3}$ MLCT population, in order to optimize photochemical performance.
\end{abstract}




\section{Introduction}

Light harvesting systems based on first-row transition metals like iron are attractive for large-scale application due to their abundance and non-toxic properties. In a light harvesting complex, the absorption of light creates a charge separated state and the study of ultrafast photo-induced dynamics has recently received considerable attention. $[1,2,3,4,5,6,7]$ The ultrafast progression of excited states after the initial light absorption is determined by the shapes and crossings of the excited state potential energy surfaces, which determine the photophysical and photochemical properties of the complexes and how they can be used. A challenge is to manipulate the positions and shapes of these potential energy surfaces, such that the charge separated state becomes sufficiently long lived for reducing or oxidizing catalysts/semiconductor acceptor systems. Traditional low spin $\mathrm{Fe}^{\mathrm{II}}$ - polypyridyl complexes generally show ultrafast $<100$ fs decay of metal to ligand charge transfer states (MLCT) into metal centered (MC) states. [8] For instance, in the extensively studied prototype $\mathrm{Fe}^{\mathrm{II}}$ molecule $\mathrm{Fe}^{\mathrm{II}}(\mathrm{bpy})_{3}$ (bpy $=2,2^{\prime}-$ bipyridine), the charge separated MLCT state deactivates on an ultrafast timescale into high spin MC states. $[9,10] \mathrm{Sim}-$ ilar ultrafast transitions into ${ }^{3} \mathrm{MC}$ states have been observed and described for ruthenium sensitizer complexes.[11, 12, 13] By de-stabilizing the MC scavenger states we, and other groups, have recently developed iron complexes with significantly slower deactivation of the MLCT states.[14, 15, 16, 17, 18, 19, 20, 21] This makes the iron carbene complexes interesting as a promising new class of photosensitizers [22], with recently demonstrated capability to inject electrons efficiently into a $\mathrm{TiO}_{2}$ substrate, and carry out bimolecular oxidation and reduction processes. $[17,15]$ Ultrafast optical measurements in combination with quantum chemical calculations have provided significant insight into the excited state structure underlying this remarkable improvement of photochemical properties. [23, 24]

As an element-specific technique x-ray spectroscopy is a powerful tool to probe the electronic structure of the metal site and surrounding ligands. With the recent advent of x-ray free electron laser (XFEL) facilities with high flux and a temporal resolution better than $30 \mathrm{fs}[25]$ it has become possible to identify the nature of the excited states directly.[10, 26, 27, 28, 29, 30, 31, 32] In these studies the oxidation state, spin and charge transfer charac- ter of the molecular state was identified by modeling the measured time resolved spectra with a linear combination of measured or calculated static reference spectra. Here, we use ultrafast $\mathrm{K}_{\alpha}$ and $\mathrm{K}_{\beta} \mathrm{x}$ ray emission spectroscopy (XES) to investigate the excited state dynamics of one of the recently introduced $\mathrm{Fe}^{\mathrm{II}}$ carbene complexes, $\mathrm{Fe}^{\mathrm{II}}(\mathrm{bpy})(\mathrm{btz})_{2}\left(\mathrm{PF}_{6}\right)_{2}$ where btz is 4,4 '-bis $(1,2,3$-tri-azol-5-ylidene) with significantly altered photophysics compared to prototype polypyridyl $\mathrm{Fe}^{\mathrm{II}}$ complexes like $\mathrm{Fe}^{\mathrm{II}}(\mathrm{bpy})_{3} \cdot[33]$

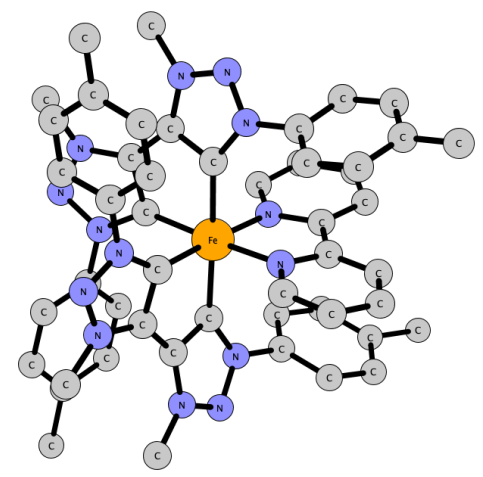

Figure 1: Bidentate $\mathrm{Fe} \mathrm{e}^{\mathrm{II}}$ complex measured in this paper, the hydrogen atoms are hidden.

Several of these complexes have been characterized by transient optical spectroscopy to have a $\sim 10$ ps or longer excited state lifetime that manifests itself both in excited state absorption features originating from persistent population of a MLCT excited state, as well as ground state recovery on the same timescale.[33, 34] These timescales are quite similar with recent results from time resolved x-ray measurements for $\mathrm{Fe}^{\mathrm{II}}$ (bpy) $(\mathrm{CN})_{4}[35]$ ascribed to a $\sim 20$ ps long-lived population of a ${ }^{3} \mathrm{MLCT}$ state. This state decayed to the ground state without undergoing noticeable spin transition to a metal centered state. These times are however noticeably different from the $\sim 260$ ps lifetime obtained in a recent x-ray scattering study and assigned to a prolonged population of a high-spin MC state.[36]

One aspect of particular current interest concerns the experimental distinction between triplet states of MLCT and spectroscopically elusive MC character in the decay cascade on ultrafast to intermediate timescales in the range of 1 ps to $100 \mathrm{ps}$. This includes systems with intermediately destabilized MC states as the emerging iron carbene photosensitizers.[37, 38] The new results obtained here in particular show that the conventional picture of a consecutive or parallel progression through a number of excited states has to be revised to a branched decay involving hot (vibra- 
tionally unrelaxed) and cold (vibrationally relaxed) de-excitation pathways through $\mathrm{CT}$ and MC states as has also been recognized by other groups. [39] This significantly enriches our understanding of the factors limiting the photochemical efficiency of this type of complexes.

\section{Description of the experiment}

We dissolved the molecule into anhydrous acetonitrile to $21 \mathrm{mMol} / \mathrm{l}$ and measured the dynamics in a round $30 \mu \mathrm{m}$ jet with the recycled solution in an inert gas atmosphere. The interaction region was pumped with $400 \mathrm{~nm} 70 \mathrm{fs}$ pulses at a fluence of $0.85 \mathrm{~mJ} / \mathrm{mm}^{2}$ predominantly within the linear absorption regime and probed near co-linearly in a $10 \mu \mathrm{m}$ region with the $8.5 \mathrm{keV}$ beam of the LCLS XFEL. The induced nonresonant $\mathrm{K}_{\beta}$ emission of the central iron atom with a maximum at $7058.2 \mathrm{eV}$ was detected after different time intervals from the photo-excitation on a $140 \mathrm{k}$ Cornell-SLAC PIXEL Array Detector (CSPAD) after dispersion on four cylindrical bent Ge $\langle 620\rangle$ crystals.[40, 41, 42]

The $\mathrm{K}_{\alpha}$ x-ray fluorescence was collected at $6404 \mathrm{eV}$, corresponding to the maximum intensity, with a single spherically bent Ge $\langle 440\rangle$ crystal in Johann geometry on a second 140k CSPAD. Each pump-probe exposure was recorded separately and binned into a relative arrival time using the timing tool and selected pump-probe delay. The presented short timescale data originates from one run in which we selected a fixed pump-probe delay and used the arrival time jitter of the x-rays to probe a variety of time delays until $1.5 \mathrm{ps}$ after the pump event. During a second run a series of longer time delays were selected to probe the evolving dynamics on a longer timescale up to $300 \mathrm{ps}$. In both cases the time resolution of $\sim 130 \mathrm{fs}$ originates from the convolution of the $70 \mathrm{fs}$ FWHM excitation pulse, with the $20 \mathrm{fs}-50 \mathrm{fs}$ duration of the coherent SASE pulse and the ability of the timing tool to determine the relative arrival time of the two pulses.[42]

During the data reduction the recorded images of the $\mathrm{K}_{\beta}$ spectra were compensated for the varying gain mode of the CS-pad, the background rejected by a threshold and the AD values converted into single photon counts. The images were then integrated into energy spectra along the von-Hamos focal axis and crystal misalignment corrected by a previously described procedure.[43]

\section{Results}

Figure 2 shows a series of $K_{\beta}$ spectra measured at selected time-delays after excitation A) together with a series of reference spectra for different spin states B). We use two independent approaches to model the temporally evolving excited state $\mathrm{K}_{\beta}$ spectra shown in Figure 2 A). First we followed the previously established approach to deconvolute the spectrum at each time point with a linear combination of the reference spectra shown in Figure 2 B).[44, 31]

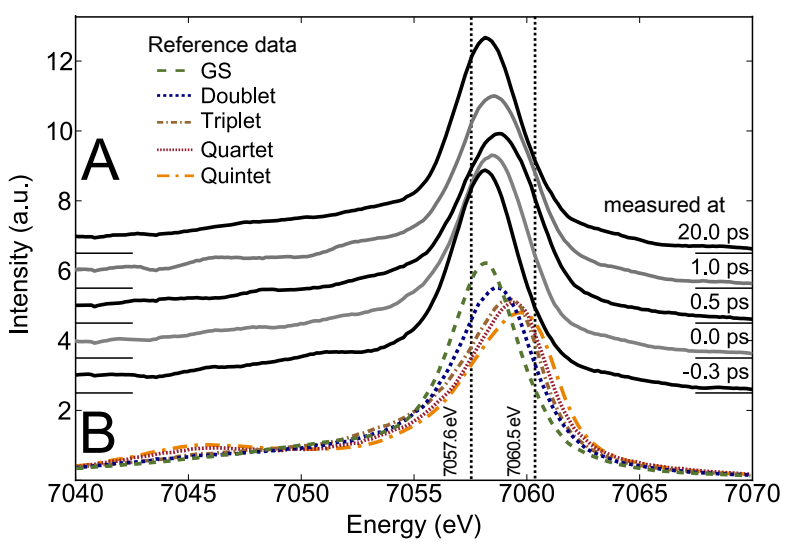

Figure 2: Measured $\mathrm{K}_{\beta}$ XES spectra of $\left[\mathrm{Fe}^{\mathrm{II}}(\mathrm{bpy})(\mathrm{btz})_{2}\right]\left(\mathrm{PF}_{6}\right)_{2}$ at a different time scale $\mathrm{A}$, reference $\mathrm{K}_{\beta}$ XES spectra for different spin state B.

In this approach no prior assumption is made which dynamic model the molecule is following except for the selection of what states to include in the de-convolution. In this language the MLCT excited states would correspond to a doublet, or quartet after an intersystem crossing and the MC states corresponds to a triplet or quintet reference state (please see SI for further information). As references for this deconvolution we used for a doublet: $\left(\left[\mathrm{Fe}^{\mathrm{III}}(\text { bpy })_{3}\right]^{3+}\right)$, a triplet: $\left(\mathrm{Fe}^{\mathrm{II}}\right.$ phtcy, phtcy $=$ phthalocyanine), a quartet: ( $\mathrm{Fe}^{\mathrm{III}}$ phtcy) and a quintet: $\left(\mathrm{Fe}^{\mathrm{IV}}(\text { Phen })_{2}(\mathrm{NCS})_{2}\right.$, Phen $=$ phenanthroline, NCS $=$ isothiocyanate). The ground state of these ligands is strongly influenced by the $\sigma$-donation and $\pi$ backbonding character of the ligand field. To achieve a good agreement with the measured ground-state we used as model the linear combination of the singlet $\mathrm{Fe}^{\mathrm{II}}$ complexes $\left[\mathrm{Fe}^{\mathrm{II}}(\mathrm{bpy})_{3}\right]\left(\mathrm{PF}_{6}\right)_{2} \quad(75 \%)$ and $\left[\mathrm{Fe}^{\mathrm{II}}(\mathrm{CN})_{6}\right](25 \%)$. Creating similar mixes of reference spectra for the excited states is not feasible due to the lack of isolated states at other time points and the thus limited statistical certainty. The challenge of this approach is thus the use of reference spectra that are potentially slightly different from the actual 
spectra of a given state, introducing sources of error.

Modelling of the excitation fraction allows the conclusion that in this experiment $\approx 8 \%$ of the excited fraction of molecules have absorbed a second photon in the excited state, leading to a very long lived state that manifests as an oxidized/ionized state at the iron center. This long lived state was then taken into account in the kinetic and spectral modeling.
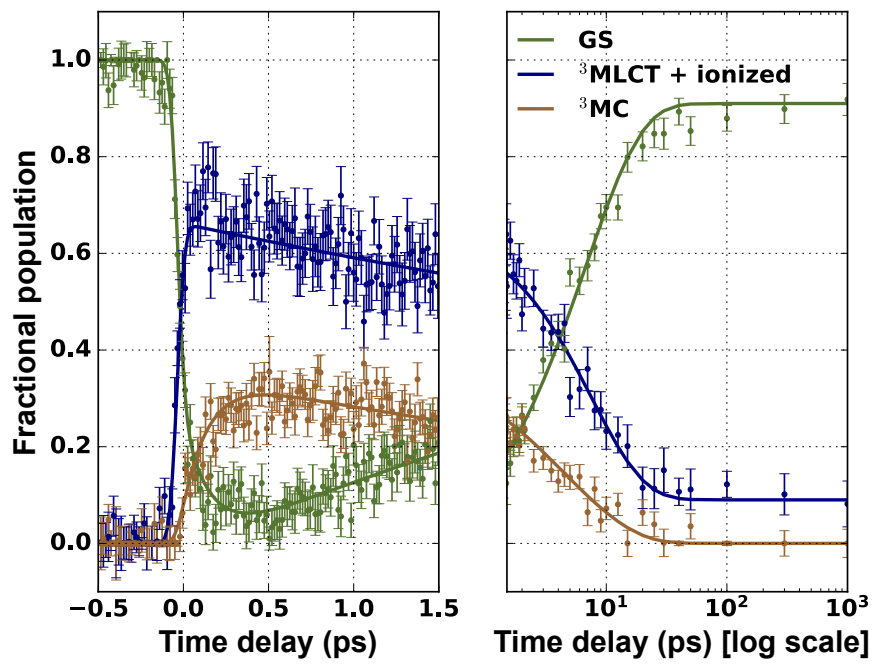

Figure 3: Comparison of population parameters as a function of time gained by the linear combination of reference spectra for each time point and the model formed by global analysis. The fractional population can be understood as the fraction of excited molecules that are in this state.

The result of forming a linear combination of model spectra for each time point is a set of parameters representing the population in each spin/excitation state. For a good description of the temporal evolution of the measured $\mathrm{Fe}-\mathrm{K}_{\beta}$ XES spectrum in Figure 2 the model spectra of the ground state (GS), ${ }^{3} \mathrm{MLCT}$ and ${ }^{3} \mathrm{MC}$ states are required. Figure 3 shows the temporal evolution of population of these states, with an assigned standard confidence interval. Linear combinations of model spectra without the ionized state, or with the involvement of the quintet MC state were tested, but led to a worse description of the measured data, as judged from an increased local (larger uncertainty) and total error ( $\chi^{2}$ of the fit). The ${ }^{1}$ MLCT state was omitted from this plot as its typical lifetime is shorter than the instrument response function and the ${ }^{1} \mathrm{MLCT}$ and ${ }^{3} \mathrm{MLCT} \mathrm{K}_{\beta}$ spectra are very similar. The state population dynamics resulting from the model spectra based analysis does not itself provide a characterization of the temporal evolution in terms of exponential time constants. The discussion below of the population dynamics is therefore quantified with the help of the time constants generated by the global analysis method discussed below; as can be seen from Figure 3 there is a very good agreement between the temporal evolution generated by the two methods.

The population dynamics resulting from model spectra fitting (Figure 3) exhibits an ultrafast "bleach" of the ground state and a delayed ps-scale exponential recovery. We observe an immediate formation of the ${ }^{3} \mathrm{MLCT}$ state, which has a singleexponential decay rate identical to the rate of the GS recovery. A fraction ( $\sim 30 \%)$ of the ${ }^{3} \mathrm{MC}$ population forms within the time resolution of the experiment. The $\sim 0.7$ fractional population of the ${ }^{3}$ MLCT state and only 0.3 of the ultrafast ${ }^{3} \mathrm{MC}$ formation suggests another relaxation pathway from the ${ }^{3} \mathrm{MLCT}$ state. The nature of this path becomes clear when we consider the decay of the ${ }^{3} \mathrm{MC}$ population - it decays with the same delayed single exponential kinetics as the ${ }^{3} \mathrm{MLCT}$ decay and GS recovery. Since the ${ }^{3} \mathrm{MC}$ state is expected to be populated from the ${ }^{3} \mathrm{MLCT}$ state (due to its significantly lower energy[33]) and both states decay with the same time constant (7.6 ps), this strongly suggests a relaxation pattern where the ${ }^{3} \mathrm{MLCT}-{ }^{3} \mathrm{MC}$ process is the rate limiting step in the sequence ${ }^{3} \mathrm{MLCT}-{ }^{3} \mathrm{MC}-\mathrm{GS}$. For ${ }^{3} \mathrm{MC}$ and ${ }^{3} \mathrm{MLCT}$ decays (and GS recovery) to be the same, the ${ }^{3} \mathrm{MC}$ - GS decay must be much faster than the ${ }^{3} \mathrm{MLCT}-{ }^{3} \mathrm{MC}$ process. This so called "inverted kinetics" shows up as a delayed rise in the ${ }^{3} \mathrm{MC}$ and GS kinetics, with a fitted time constant of $2.2 \mathrm{ps}$ for the ${ }^{3} \mathrm{MC}$ to GS step. The faster depopulation then population ( 2.2 vs $7.6 \mathrm{ps}$ ) of the ${ }^{3} \mathrm{MC}$ state implies that no visible population builds up through this channel, explaining the "missing" fractional population. This behavior was already observed in optical TA measurements on the first FeNHC synthesized.[21] The partial ultrafast formation of the ${ }^{3} \mathrm{MC}$ state implies that there will be a 2.2 ps decay of the state with the same amplitude, as well as the same partial recovery of the ground state. This decay will to a certain extent cancel the $2.2 \mathrm{ps}$ rise in the inverted kinetics of the ${ }^{3} \mathrm{MC}$ majority population, but because this is the dominating part the rise is nevertheless clearly observable.

The global analysis fitting returns the ${ }^{3} \mathrm{MC}$ formation time constant as $150 \mathrm{fs}$, on the limit of the time resolution of the experiment, and the ${ }^{1} \mathrm{MLCT}$ to ${ }^{3} \mathrm{MLCT}$ transition cannot be resolved with any certainty because of very high rate and similar spectra. 
Therefore, it is difficult to judge whether the ultrafast population of the ${ }^{3} \mathrm{MC}$ state occurs directly from the ${ }^{1} \mathrm{MLCT}$ state or from the ${ }^{3} \mathrm{MLCT}$ state following ${ }^{1} \mathrm{MLCT}$ to ${ }^{3} \mathrm{MLCT}$ ISC. In the latter case, the ISC from the ${ }^{1}$ MLCT state would have to occur to a hot ${ }^{3} \mathrm{MLCT}$ state, followed by a branched decay to the ${ }^{3} \mathrm{MC}$ and cold ${ }^{3} \mathrm{MLCT}$ states, in order to be compatible with the observed branching ratio.

This is consistent with the generally fast cooling of charge transfer states. Optical TA measurements on similar FeNHC complexes suggesting $\ll 100$ fs ${ }^{1} \mathrm{MLCT}-{ }^{3} \mathrm{MLCT}$ ISC $[3,32,39,43,45,46]$ would support this scenario. Time constants and associated amplitudes of the processes are summarized in the conclusions.

A to our knowledge novel approach in the field of time resolved XES is a reference free global analysis scheme which is often used in the field of transient optical absorption spectroscopy.[47, 48] In the global analysis approach used here, a parametric model based upon a set of differential equations is created for all time points. In a separate step the optimal spectral representation is calculated by solving the equation system with the observed intensity as a goal (see SI for further details). This approach avoids the use of rigid reference spectra, which may be difficult to obtain for these complexes with strong metal-ligand interaction. The optimal spectral representation is calculated anew for each step of the optimization. In the progress of the analysis a number of potential models are generated, refined with a matrix of starting parameters, and evaluated against measured spectra.

In transient optical spectroscopy an initial approach often used to get a first qualitative picture of the processes and time scales involved, is to perform single color kinetic measurements, i.e. to measure the excitation pulse induced dynamics at a few different probe wavelengths, rather than measuring the broad-band full spectral response. The analysis of single kinetic traces is also less demanding than that of the full spectral temporal evolution. The kinetic traces in Figure 4 are the single color kinetics taken at two different energies in the $\mathrm{Fe}-\mathrm{K}_{\beta}$ XES spectrum in Figure 2, $7057.6 \mathrm{eV}$ and $7060.5 \mathrm{eV}$, on the low- and high-energy side of the spectrum, respectively. Kinetics measured at $7057.6 \mathrm{eV}$ exhibits a decreasing signal as time progresses, while kinetics at $7060.5 \mathrm{eV}$ shows an increasing signal. The reference spectra now show that the decrease/increase of signal at $7057.6 / 7060.5 \mathrm{eV}$ is a result of increas- ing spin density on the iron atom with a rise time of $\sim 150 \mathrm{fs}$, indicating the presence of an ultrafast intersystem crossing, in agreement with many previous studies on iron complexes. [3, 32, 39, 43, 45, 46] At later times we observe a recovery of the excitationinduced spin momentum, but it does not fully recover to the ground state level within the $1 \mathrm{~ns}$ experimental window, due to the long lived oxidized/ionized state formed through excited state absorption.
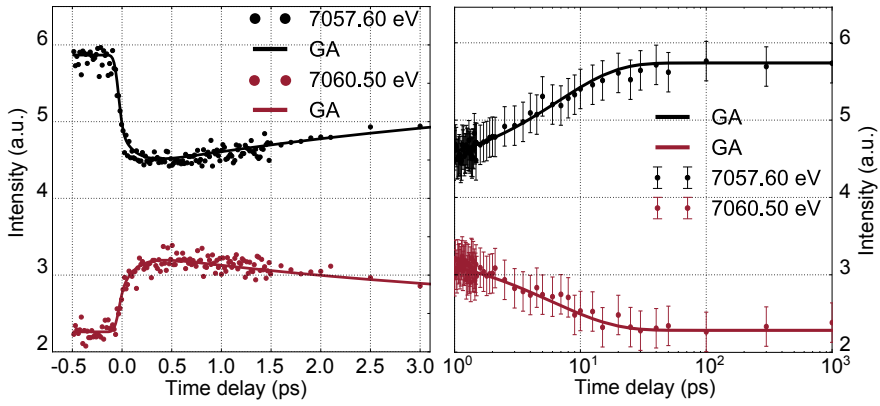

Figure 4: Kinetic spectrum of two single energetic slices extracted from the measured $\mathrm{Fe}-\mathrm{K}_{\beta}$ spectra.

Left: Focusing on fast kinetics. Dots represent the observed intensity in a single temporal bin as defined by the timing tool. Right: Focusing on temporal development over multiple picoseconds. Error bars represent the variance of measurements within a temporal bin.

The model of the involved states for the analysis of single color kinetic data (Figure 4) as well as the full spectral evolution (Figure 5) is the same as emerging from the model spectra based analysis (Figure 5) of the measured $\mathrm{Fe}-\mathrm{K}_{\beta}$ XES spectrum: An ultrafast, unresolved ${ }^{1} \mathrm{MLCT}$ to a hot (not relaxed) ${ }^{3} \mathrm{MLCT}$ ISC, followed by a branched decay of the hot ${ }^{3} \mathrm{MLCT}$ state into the ${ }^{3} \mathrm{MC}$ state and relaxed (cold) ${ }^{3} \mathrm{MLCT}$ state, which decays into the ${ }^{3} \mathrm{MC}$ state; the ${ }^{3} \mathrm{MC}$ state finally decays back to ground state. The formation of the permanently (on this time scale) oxidized state through excited state absorption from the ${ }^{1}$ MLCT state was also included in this modeling. As already mentioned above, the two ultrafast processes ${ }^{1} \mathrm{MLCT}$ to ${ }^{3} \mathrm{MLCT}$ and partial decay to the ${ }^{3} \mathrm{MC}$ state cannot clearly be distinguished as two separate processes, because they both are similar or faster than the measurement response function. In principle, the ultrafast formation of part of the ${ }^{3} \mathrm{MC}$ population could occur from the ${ }^{1} \mathrm{MLCT}$ state, but we choose the relaxation scheme summarized in the conclusions, based on results from optical TA on similar molecules.[3, 32, 39, 43, 45, 46] A comprehensive discussion of the other, less successful, tested models 

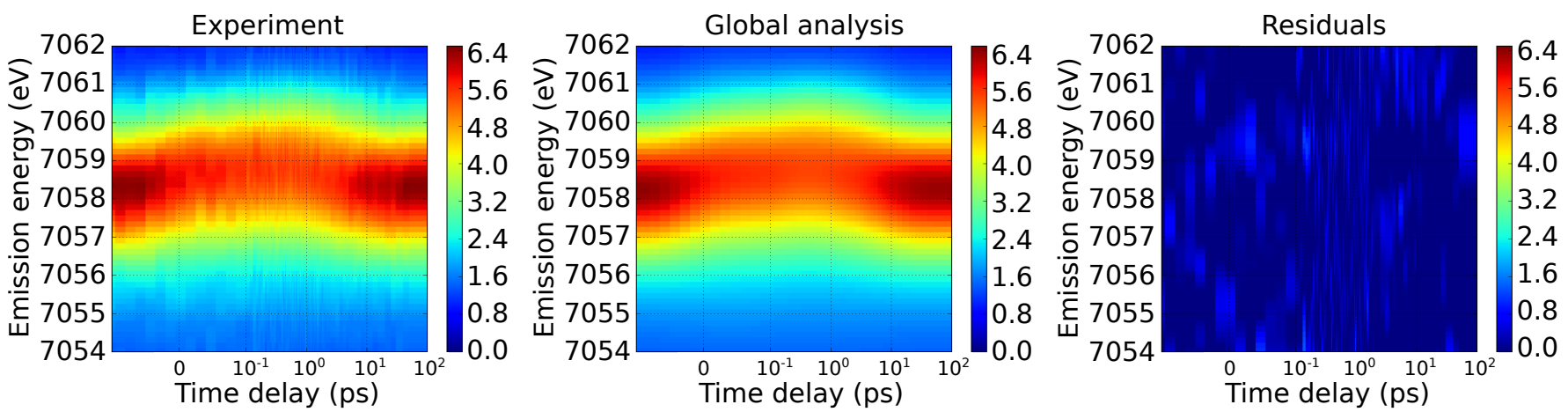

Figure 5: Comparison of Measured Matrix of spectral intensity vs time (left) with model (middle) and difference between model and data (right)

as well as the used rate equations are given in the supplementary information.

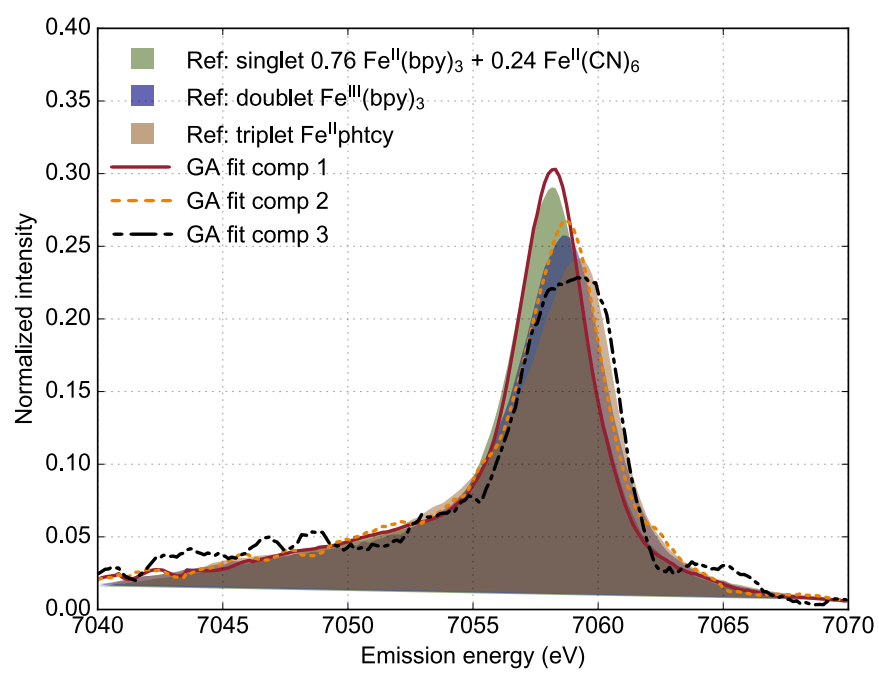

Figure 6: (solid lines) Spectra extracted from Global modelling of full kinetic dataset, often called Decay associated spectra, compared to reference spectra for identification

Free parameters in the global analysis fitting of single color kinetics and XES spectral evolution are the lifetimes and the branching ratio from the hot ${ }^{3} \mathrm{MLCT}$ state to the ${ }^{3} \mathrm{MC}$ and relaxed ${ }^{3} \mathrm{MLCT}$ states. The result of this modelling is a full $2 \mathrm{D}$ map of spectral intensity vs. time that was formed without imposing a particular spectrum and that used the statistical information of the whole dataset. Figure 5 shows the measured $\mathrm{Fe}-\mathrm{K}_{\beta}$ XES spectrum as a function of time, the time dependent spectrum obtained from the global analysis fitting and residuals of the analysis with a feature-free error matrix. The solid lines in Figure 4 labeled "GA", and in Figure 3 are a narrow band spectral integration of the full 2D map. It is encouraging to see that the global analysis approach generates kinetics that almost perfectly traces the temporal evolution of the population of states obtained from the model spectra based analysis (Figure $3)$.

It should be noted that all analysis and model optimization was performed on the absolute recorded $\mathrm{K}_{\beta}$ spectra. This reduces noise and avoids the introduction of spectral errors due to changes of the ground state over time, e.g. due to sample degradation. The calculated spectra can be understood as species associated spectra and be compared to reference spectra and identified with spin/charge transfer states as has been done in Figure 6. The small deviations between the global analysis spectra and reference spectra can originate from the different bonding environments in the studied molecule as compared to the molecules used for reference spectra, experimental conditions like the spectral deconvolution, or statistical limitations of minority species. During the analysis we do not enforce the use of a specific spectrum and are thus robust against influences that are present for all spectra (like misalignment of the spectrometer), or insufficient reference spectra quality. It thus appears as a useful strategy to use both analysis methods in parallel and ensure that one receives good agreement between the two methods like in Figure 3.

An independent verification of this modelling can be achieved by using the simultaneously collected $\mathrm{K}_{\alpha}$ line. It has been shown by us and others previously that the intensity and width of the $\mathrm{Fe} / \mathrm{Co} \mathrm{K}_{\alpha}$ emission spectrum is a good marker of the total spin momentum at the metal center. $[29,49,50]$ We measured the $\mathrm{K}_{\alpha}$ emission at $6404 \mathrm{eV}$ and can use this correlation to monitor the evolution of the total spin momentum in the molecule. Figure 7 shows the measured intensity changes and we analyze the signal independently of the previous analysis in the left-hand panel and then overlay the results we gained from the $\mathrm{K}_{\beta}$ analysis with the data in the middle and right-hand panel. 

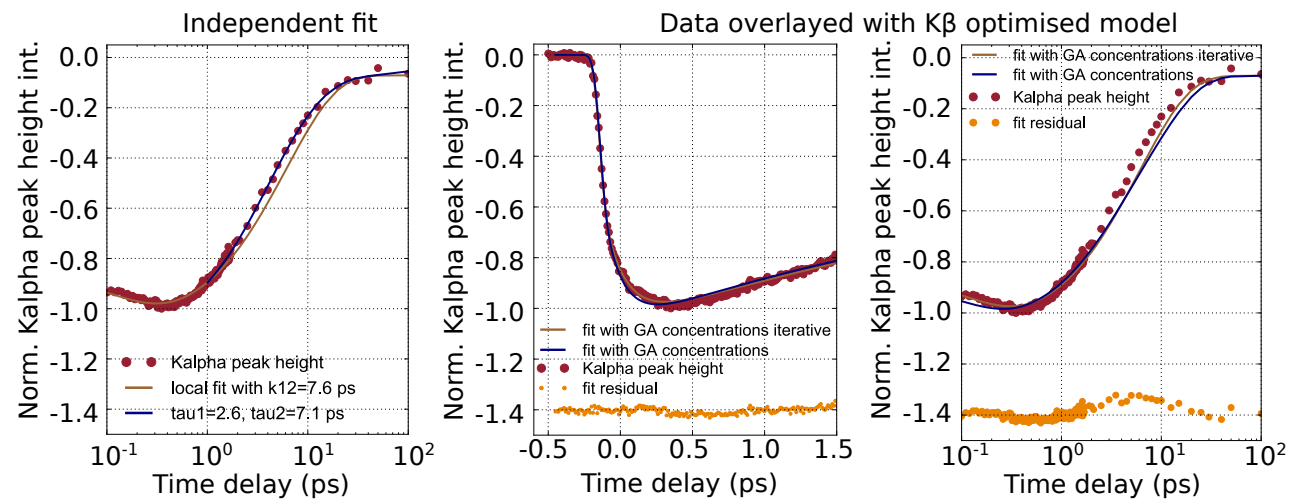

Figure 7: Single wavelength $\mathrm{K}_{\alpha}$ emission spectrum measured in parallel with $\mathrm{K}_{\beta}$ spectrum. Left: Measured data independently modeled with single and double component exponential decay. Middle and right: Measured data with overlayed model.

In the left-hand panel the data was modeled with one and two consecutive exponential decay functions, respectively, given arbitrary intensity variation. In order to superimpose the previously obtained population factors we convert the population of the excited states into a change of the total spin momentum at the iron. The state ${ }^{1 / 3} \mathrm{MLCT}$ thus corresponds to a change of $\Delta \mathrm{S}=\frac{1}{2}$ vs. the GS, the ${ }^{3} \mathrm{MC}$ with $\Delta \mathrm{S}=1$ and the ${ }^{5} \mathrm{MC}$ state with $\Delta \mathrm{S}=2$ at the iron center.

In the independent fit two exponential functions are required to explain the measured kinetics, reproducing in general the same time constants. The model created by optimizing the measured dynamics with the $\mathrm{K}_{\beta}$ spectra also shows a good agreement with the here measured spectrum. This approach is particularly valuable to test for the involvement of high spin states. If e.g. only a small fraction of the complex would decay over a quintet state, the subtle changes to the total $\mathrm{K}_{\beta}$ spectrum might be difficult to identify. As the difference of the total spin moment change is $\mathrm{x} 2$ for the ${ }^{5} \mathrm{MC}$ compared to the ${ }^{3} \mathrm{MC}$ the signal is significantly clearer in the $\mathrm{K}_{\alpha}$ spectrum, allowing exclusion of models involving high spin states.

\section{Discussion}

Both optically bright and dark states are important players in the photochemical behavior of transition metal complexes, and optical spectroscopy only provides part of the complete picture. Here we have used ultrafast x-ray emission spectroscopy to monitor the relaxation pathways and identify the nature (spin state) of involved excited states following photoexcitation. Through the $\mathrm{K}_{\beta}$ emission spectrum we observed an ultrafast and strong rise of the spin momentum on the iron atom (Figure 4). This spin increase is analyzed with two different methods, reference spectra based analysis of the temporal evolution of the $\mathrm{K}_{\beta}$ spectrum, and a global analysis approach "inspired" by optical TA spectroscopy. In very good mutual agreement, both methods show that $\mathrm{Fe}^{\mathrm{II}}(\mathrm{bpy})(\mathrm{btz})_{2}$, following photoexcitation and ultrafast ISC to a hot ${ }^{3}$ MLCT state, relaxes along a branched pathway back to the ground state (Figure 8 ). This relaxation pattern is in addition supported by the temporal evolution of the $\mathrm{K}_{\alpha}$ spectrum. In accordance with recent results from optical TA spectroscopy and quantum chemistry calculations a majority $(\sim 70 \%)$ of the population of excited molecules return to the ground state via inverted kinetics through a relaxed ${ }^{3} \mathrm{MLCT}$ state and the ${ }^{3} \mathrm{MC}$ state, where the transition ${ }^{3} \mathrm{MLCT} \rightarrow{ }^{3} \mathrm{MC}$ is rate limiting (7.6ps) and the transition ${ }^{3} \mathrm{MC} \rightarrow \mathrm{GS}$ is much faster $(2.2 \mathrm{ps})$. Along a previously unknown pathway $\sim 30 \%$ of the ${ }^{3} \mathrm{MLCT}$ state population is "short circuited" by an ultrafast ( $\sim 150 \mathrm{fs}$ ) decay to the ${ }^{3} \mathrm{MC}$ state. From a photochemical and application point of view this implies that $\sim 30 \%$ of the excited molecules are dumped through an ultrafast process into a photochemically inactive state, which in addition is very short lived ( $2.2 \mathrm{ps})$.

The here observed lifetime of the relaxed ${ }^{3} \mathrm{MLCT}$ state is shorter than previously measured with optical transient absorption spectroscopy ( $\sim 13 \mathrm{ps})$. Part of the reason is the different excitation wavelength (705 nm vs. $400 \mathrm{~nm}$ used here) and analysis method used in the two experiments. Another reason may be difficulties in state assignment. We performed new optical TA measurements using $400 \mathrm{~nm}$ excitation and the branched relaxation model of Figure 8 to analyze the response. This gives a $9.2 \mathrm{ps}$ lifetime of the rate limiting ${ }^{3} \mathrm{MLCT}-{ }^{3} \mathrm{MC}$ step, close to the $7.6 \mathrm{ps}$ determined with the $\mathrm{x}$-ray probe. The ${ }^{3} \mathrm{MC}$ to 
GS process is now characterized by a $2.3 \mathrm{ps}$ lifetime, identical within experimental error to the $2.2 \mathrm{ps}$ obtained in the x-ray measurements. A small fraction of the MC state, not visible in the x-ray experiment decays with $13.6 \mathrm{ps}$. (See also the supplementary information)

As mentioned above, since the development of this complex, other FeNHC molecules with CT state lifetimes up to $\sim 2$ ns have been developed.[15] Although these molecules are highly interesting for photochemical applications, their photophysics and photochemistry have so far only been characterized with optical spectroscopy. This implies that the involvement of quantum yield and efficiency reducing processes like the ultrafast ${ }^{3} \mathrm{MLCT} \rightarrow{ }^{3} \mathrm{MC}$ process identified here is unknown and might reduce their overall efficiency. Our work shows that a combination of optical and xray methods, providing sufficient temporal resolution and state/spin selectivity is required for a complete characterization of the excited state relaxation pattern, involving both relaxation rates and yields of optical bright and dark states. With this knowledge we are well armed to modify the ligand sphere and binding patterns to optimize photochemical and electrochemical properties of the these promising molecules.

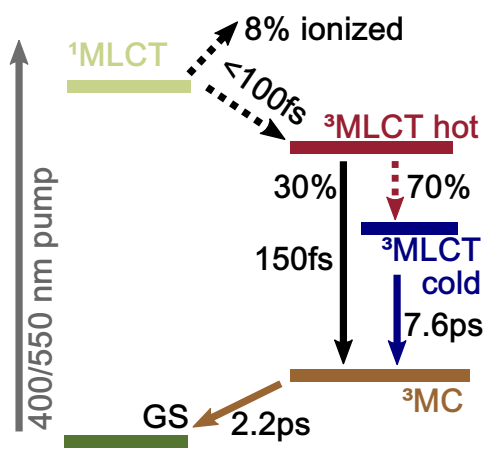

Figure 8: Jablonski diagram with suggested dynamics as determined in this study.

\section{Conclusion}

We have used x-ray spectroscopic techniques to investigate a $\mathrm{Fe}^{\mathrm{II}}$ transition metal complex of the recently developed nitrogen heterocyclic carbene type, which have drastically extended CT state lifetimes as compared to traditional polypyridyl complexes. Measurement and analysis of the temporal evolution of the $\mathrm{K}_{\beta}$ and $\mathrm{K}_{\alpha}$ spectra following photoexcitation helped us to identify and quantify the population dynamics of the different excited states involved in the relaxation cascade. The analysis involved two meth- ods for extracting excited state dynamics and spectra, a model spectra based and global analysis of the time dependent $\mathrm{K}_{\beta}$ spectrum. This analysis was further supported by recording the temporal evolution of the $K_{\alpha}$ spectrum, whose peak intensity is a sensitive marker of the total spin momentum of the molecule. The results of this analysis can be summarized as three major findings: 1) Substantiating previous conclusions from optical TA measurements and quantum chemical calculations we conclude that the ${ }^{5} \mathrm{MC}$ state is never populated in the relaxation from the ${ }^{3}$ MLCT state back to ground state. Thus, a major effect of the increased electron density on the Fe-center accomplished by the NHC ligands is to move the ${ }^{5} \mathrm{MC}$ state out of the relaxation pathway; 2) A previously unknown relaxation channel is identified: an ultrafast sub-ps decay from a hot ${ }^{3} \mathrm{MLCT}$ state to the ${ }^{3} \mathrm{MC}$ state, in competition with vibrational cooling of the ${ }^{3} \mathrm{MLCT}$ state. This process constitutes a partial "short circuit" of the ${ }^{3} \mathrm{MLCT}$ state and reduces the yield of molecules available for photochemical functions. 3) The ultrafast deactivation of the ${ }^{3}$ MLCT state of Fe-polypyridyl complexes, and $\mathrm{Fe}^{\mathrm{II}}(\text { bpy })_{3}$ in particular, has been explained as a sequential process involving the ${ }^{5} \mathrm{MC}$ and ${ }^{3} \mathrm{MC}$ states[43, 51, 52, 26, 53, 54], or a direct one-step process[3]. The present results, highlighting a branched decay of a hot ${ }^{3} \mathrm{MLCT}$ state, may perhaps offer a possibility to reconcile these apparently disagreeing results: also in the Fe-polypyridyl complexes there is perhaps a branched decay of the ${ }^{3} \mathrm{MLCT}$ state, but various time resolved methods (e.g. optical and xray) used to monitor the relaxation processes have different sensitivity to the two pathways and states.

\section{Acknowledgments}

PP acknowledges support from the Crafoord Foundation, the Knut and Alice Wallenberg Foundation (KAW), the Swedish Research Council (VR), the Swedish Energy Agency (Energimyndigheten), and the Swedish Foundation for Strategic Research (SSF). JU acknowledges support from the Crafoord Foundation, the Knut and Alice Wallenberg Foundation (KAW) and from the Trygger Foundation for this research. The DTU-affiliated authors gratefully acknowledge DANSCATT for supporting the beamtime efforts. M. M. N., M. G. L., E. B., A. O. D., and K. B. M. thank the Independent Research Fund Denmark for financial support under Grants No. DFF-4002-00272 and No. DFF-8021-00347B. AOD 
acknowledges support from the Icelandic Research Fund, Grant 196279-051. S. E. C. acknowledges funding from the Helmholtz Recognition Award. The ELI-ALPS project (GINOP-2.3.6-15-2015-00001) is financed by the European Union and co-financed by the European Regional Development Fund. This work is in part financed by the 'Lendület' (Momentum) Program of the Hungarian Academy of Sciences (LP2013-59), the Government of Hungary and the European Regional Development Fund under Grant VEKOP-2.3.2-16-2017-00015, and the National Research, Development and Innovation Fund (NKFIH FK 124460). Our thanks to the SLAC/LCLS facility and the staff from XPP for granting us beamtime and enabling this study.

\section{References}

[1] C. S. Ponseca, P. Chábera, J. Uhlig, P. Persson, V. Sundström, Chemical Reviews 2017, 117, 10940-11024.

[2] M. Chergui, E. Collet, Chemical Reviews 2017, $117,11025-11065$.

[3] G. Auböck, M. Chergui, Nature Chemistry 2015, 7, 629-633.

[4] O. S. Wenger, Chemistry - A European Journal 2019, 25, 6043-6052.

[5] E. R. Young, A. Oldacre, Science 2019, 363, 225-226.

[6] J. K. McCusker, Science 2019, 363, 484-488.

[7] O. S. Wenger, Journal of the American Chemical Society 2018, 140, 13522-13533.

[8] J. K. McCusker, A. Vlček, Accounts of Chemical Research 2015, 48, 1207-1208.

[9] W. Gawelda, A. Cannizzo, V. T. Pham, F. van Mourik, C. Bressler, M. Chergui, Journal of the American Chemical Society 2007, 129, 8199-8206.

[10] P. Wernet, Philosophical Transactions of the Royal Society A: Mathematical, Physical and Engineering Sciences 2019, 377, 20170464.

[11] Q. Sun, B. Dereka, E. Vauthey, L. M. L. Daku, A. Hauser, Chemical Science 2017, 8, 223-230.
[12] Q. Sun, S. Mosquera-Vazquez, Y. Suffren, J. Hankache, N. Amstutz, L. M. L. Daku, E. Vauthey, A. Hauser, Coordination Chemistry Reviews 2015, 282, 87-99.

[13] Q. Sun, S. Mosquera-Vazquez, L. M. L. Daku, L. Guénée, H. A. Goodwin, E. Vauthey, A. Hauser, Journal of the American Chemical Society 2013, 135, 13660-13663.

[14] P. Chábera, K. S. Kjær, O. Prakash, A. Honarfar, Y. Liu, L. A. Fredin, T. C. B. Harlang, S. Lidin, J. Uhlig, V. Sundström, R. Lomoth, P. Persson, K. Wärnmark, The Journal of Physical Chemistry Letters 2018, 9, 459-463, PMID: 29298063.

[15] K. S. Kjær, N. Kaul, O. Prakash, P. Chábera, N. W. Rosemann, A. Honarfar, O. Gordivska, L. A. Fredin, K.-E. Bergquist, L. Häggström, T. Ericsson, L. Lindh, A. Yartsev, S. Styring, P. Huang, J. Uhlig, J. Bendix, D. Strand, V. Sundström, P. Persson, R. Lomoth, K. Wärnmark, Science 2018, 363, 249-253.

[16] P. Chábera, Y. Liu, O. Prakash, E. Thyraug, A. El Nahhas, A. Honarfar, S. Essén, L. A. Fredin, T. C. B. Harlang, K. S. Kjær, K. Handrup, F. Ericson, H. Tatsuno, K. Morgan, J. Schnadt, L. Häggström, T. Ericsson, A. Sobkowiak, S. Lidin, P. Huang, S. Styring, J. Uhlig, J. Bendix, R. Lomoth, V. Sundström, P. Persson, K. Wärnmark, Nature 2017, 543, 695-699.

[17] T. C. B. Harlang, Y. Liu, O. Gordivska, L. A. Fredin, C. S. Ponseca, P. Huang, P. Chábera, K. S. Kjaer, H. Mateos, J. Uhlig, R. Lomoth, R. Wallenberg, S. Styring, P. Persson, V. Sundström, K. Wärnmark, Nature Chemistry 2015, 7, 883-889.

[18] P. Zimmer, P. Müller, L. Burkhardt, R. Schepper, A. Neuba, J. Steube, F. Dietrich, U. Flörke, S. Mangold, M. Gerhards, M. Bauer, European Journal of Inorganic Chemistry 2017, 2017, 1504-1509.

[19] L. Liu, T. Duchanois, T. Etienne, A. Monari, M. Beley, X. Assfeld, S. Haacke, P. C. Gros, Physical Chemistry Chemical Physics 2016, 18, 12550-12556. 
[20] P. Chabera, L. A. Fredin, K. S. Kjær, N. W. Rosemann, L. Lind, O. Prakash, Y. Liu, K. Warnmark, J. Uhlig, V. Sundstrom, A. Yartsev, P. Persson, Faraday Discussions 2019.

[21] Y. Liu, T. Harlang, S. E. Canton, P. Chábera, K. Suárez-Alcántara, A. Fleckhaus, D. A. Vithanage, E. Göransson, A. Corani, R. Lomoth, V. Sundström, K. Wärnmark, Chemical communications 2013, 49, 6412-4.

[22] Y. Liu, P. Persson, V. Sundström, K. Wärnmark, Accounts of Chemical Research 2016, 49, 1477-1485.

[23] L. A. Fredin, M. Pápai, E. Rozsályi, G. Vankó, K. Wärnmark, V. Sundström, P. Persson, The Journal of Physical Chemistry Letters 2014, 5, 2066-2071.

[24] M. Pápai, M. Abedi, G. Levi, E. Biasin, M. M. Nielsen, K. B. Møller, The Journal of Physical Chemistry C 2019, 123, 2056-2065.

[25] H. T. Lemke, K. S. Kjær, R. Hartsock, v. T. B. Driel, M. Chollet, J. M. Glownia, S. Song, D. Zhu, E. Pace, S. F. Matar, M. M. Nielsen, M. Benfatto, K. J. Gaffney, E. Collet, M. Cammarata, Nature Communications 2017, 8, 15342 .

[26] C. Bressler, C. Milne, V.-T. Pham, A. ElNahhas, v. d. R. M. Veen, W. Gawelda, S. Johnson, P. Beaud, D. Grolimund, M. Kaiser, C. N. Borca, G. Ingold, R. Abela, M. Chergui, Science 2009, 323, 489-492, PMID: 19074309.

[27] S. E. Canton, K. S. Kjær, G. Vankó, v. T. B. Driel, S.-i. Adachi, A. Bordage, C. Bressler, P. Chabera, M. Christensen, A. O. Dohn, A. Galler, W. Gawelda, D. Gosztola, K. Haldrup, T. Harlang, Y. Liu, K. B. Møller, Z. Németh, S. Nozawa, M. Pápai, T. Sato, T. Sato, K. Suarez-Alcantara, T. Togashi, K. Tono, J. Uhlig, D. A. Vithanage, K. Wärnmark, M. Yabashi, J. Zhang, V. Sundström, M. M. Nielsen, Nature Communications 2015, 6,6359 .

[28] v. T. B. Driel, K. S. Kjær, E. Biasin, K. Haldrup, H. T. Lemke, M. M. Nielsen, Faraday Discussions 2015, 177, 443-465.
[29] G. Vankó, A. Bordage, P. Glatzel, E. Gallo, M. Rovezzi, W. Gawelda, A. Galler, C. Bressler, G. Doumy, A. M. March, E. P. Kanter, L. Young, S. H. Southworth, S. E. Canton, J. Uhlig, G. Smolentsev, V. Sundström, K. Haldrup, T. B. van Driel, M. M. Nielsen, K. S. Kjaer, H. T. Lemke, Journal of Electron Spectroscopy and Related Phenomena 2013, 188, 166-171.

[30] A. H. Zewail, The Journal of Physical Chemistry A 2000, 104, 5660-5694.

[31] W. Zhang, R. Alonso-Mori, U. Bergmann, C. Bressler, M. Chollet, A. Galler, W. Gawelda, R. G. Hadt, R. W. Hartsock, T. Kroll, K. S. Kjær, K. Kubiček, H. T. Lemke, H. W. Liang, D. A. Meyer, M. M. Nielsen, C. Purser, J. S. Robinson, E. I. Solomon, Z. Sun, D. Sokaras, T. B. van Driel, G. Vankó, T.-C. Weng, D. Zhu, K. J. Gaffney, Nature 2014, 509, 345-348.

[32] M. Chergui, E. Collet, Chemical Reviews 2017, 117, 11025-11065.

[33] Y. Liu, K. S. Kjaer, L. A. Fredin, P. Chabera, T. Harlang, S. E. Canton, S. Lidin, J. Zhang, R. Lomoth, K.-E. Bergquist, P. Persson, K. Warnmark, V. Sundstrom, Chemistry-a European Journal 2014, 21, 3628-3639.

[34] Y. Liu, K. S. Kjaer, L. A. Fredin, P. Chabera, T. Harlang, S. E. Canton, S. Lidin, J. Zhang, R. Lomoth, K.-E. Bergquist, P. Persson, K. Warnmark, V. Sundstrom, Chemistry-a European Journal 2015, 21, 3628-3639.

[35] W. Zhang, K. S. Kjaer, R. Alonso-Mori, U. Bergmann, M. Chollet, L. A. Fredin, R. G. Hadt, R. W. Hartsock, T. Harlang, T. Kroll, K. Kubicek, H. T. Lemke, H. W. Liang, Y. Liu, M. M. Nielsen, P. Persson, J. S. Robinson, E. I. Solomon, Z. Sun, D. Sokaras, T. B. van Driel, T.-C. Weng, D. Zhu, K. Warnmark, V. Sundstrom, K. J. Gaffney, Chemical Science 2017, 8, $515-523$.

[36] D. Leshchev, T. C. B. Harlang, L. A. Fredin, D. Khakhulin, Y. Liu, E. Biasin, M. G. Laursen, G. E. Newby, K. Haldrup, M. M. Nielsen, K. Wärnmark, V. Sundström, P. Persson, K. S. Kjær, M. Wulff, Chemical Science 2018, 9, 405-414.

[37] L. L. Jamula, A. M. Brown, D. Guo, J. K. McCusker, Inorganic Chemistry 2014, 53, 15-17. 
[38] A. K. C. Mengel, C. Foerster, A. Breivogel, K. Mack, J. R. Ochsmann, F. Laquai, V. Ksenofontov, K. Heinze, Chemistry-a European Journal 2015, 21, 704-714.

[39] K. Magra, E. Domenichini, A. Francés-Monerris, C. Cebrián, M. Beley, M. Darari, M. Pastore, A. Monari, X. Assfeld, S. Haacke, P. C. Gros, Inorganic Chemistry 2019, 58, 5069-5081.

[40] R. Alonso-Mori, J. Kern, D. Sokaras, T.C. Weng, D. Nordlund, R. Tran, P. Montanez, J. Delor, V. K. Yachandra, J. Yano, U. Bergmann, The Review of scientific instruments 2012, 83, 073114.

[41] H. T. Philipp, M. W. Tate, S. M. Gruner, Journal of Instrumentation 2011, 6, C11006-C11006.

[42] M. Chollet, R. Alonso-Mori, M. Cammarata, D. Damiani, J. Defever, J. T. Delor, Y. Feng, J. M. Glownia, J. B. Langton, S. Nelson, K. Ramsey, A. Robert, M. Sikorski, S. Song, D. Stefanescu, V. Srinivasan, D. Zhu, H. T. Lemke, D. M. Fritz, Journal of Synchrotron Radiation 2015, 22, 503-507.

[43] K. S. Kjær, T. B. V. Driel, T. C. B. Harlang, K. Kunnus, K. Ledbetter, R. W. Hartsock, M. E. Reinhard, S. Koroidov, L. Li, M. G. Laursen, E. Biasin, F. B. Hansen, P. Vester, M. Christensen, K. Haldrup, M. M. Nielsen, A. O. Dohn, M. I. Pápai, K. B. Møller, P. Chabera, Y. Liu, H. Tatsuno, C. Timm, M. Jarenmark, J. Uhlig, V. Sundstöm, K. Wärnmark, P. Persson, Z. Németh, D. S. Szemes, Éva Bajnóczi, G. Vankó, R. Alonso-Mori, J. M. Glownia, S. Nelson, M. Sikorski, D. Sokaras, S. Canton, H. T. Lemke, K. J. Gaffney, Chemical Science 2019, 10, 5749-5760.

[44] W. Zhang, K. J. Gaffney, Accounts of Chemical Research 2015, 48, 1140-1148.

[45] W. Gawelda, V.-T. Pham, R. M. van der Veen, D. Grolimund, R. Abela, M. Chergui, C. Bressler, The Journal of Chemical Physics 2009, 130, 124520 .

[46] L. Liu, D. Agathangelou, T. Roland, O. Crégut, T. Duchanois, M. Beley, J. Léonard, P. Gros, S. Haacke, EPJ Web of Conferences 2019, 205, 09009.
[47] C. Ruckebusch, M. Sliwa, P. Pernot, A. de Juan, R. Tauler, Journal of Photochemistry and Photobiology C: Photochemistry Reviews 2012, 13, $1-27$.

[48] I. H. van Stokkum, D. S. Larsen, R. van Grondelle, Biochimica et Biophysica Acta (BBA) Bioenergetics 2004, 1657, 82-104.

[49] G. Vankó, A. Bordage, M. Pápai, K. Haldrup, P. Glatzel, A. M. March, G. Doumy, A. Britz, A. Galler, T. A. Assefa, D. Cabaret, A. Juhin, T. B. van Driel, K. S. Kjær, A. O. Dohn, K. B. Moller, H. T. Lemke, E. Gallo, M. Rovezzi, Z. Németh, E. Rozsályi, T. Rozgonyi, J. Uhlig, V. Sundstrom, M. M. Nielsen, L. Young, S. H. Southworth, C. Bressler, W. Gawelda, The Journal of Physical Chemistry $C$ 2015, 119, $5888-5902$.

[50] G. Vankó, T. Neisius, G. Molnar, F. Renz, S. Karpati, A. Shukla, F. M. F. de Groot, The Journal of Physical Chemistry B 2006, 110, $11647-53$.

[51] H. T. Lemke, C. Bressler, L. X. Chen, D. M. Fritz, K. J. Gaffney, A. Galler, W. Gawelda, K. Haldrup, R. W. Hartsock, H. Ihee, J. Kim, K. H. Kim, J. H. Lee, M. M. Nielsen, A. B. Stickrath, W. Zhang, D. Zhu, M. Cammarata, The Journal of Physical Chemistry A 2013, 117, 735-40.

[52] K. Haldrup, W. Gawelda, R. Abela, R. AlonsoMori, U. Bergmann, A. Bordage, M. Cammarata, S. E. Canton, A. O. Dohn, T. B. van Driel, D. M. Fritz, A. Galler, P. Glatzel, T. Harlang, K. S. Kjær, H. T. Lemke, K. B. Møller, Z. Németh, M. Pápai, N. Sas, J. Uhlig, D. Zhu, G. Vankó, V. Sundström, M. M. Nielsen, C. Bressler, The Journal of Physical Chemistry B 2016, 120, 1158-1168.

[53] C. Consani, M. Prémont-Schwarz, A. ElNahhas, C. Bressler, F. van Mourik, A. Cannizzo, M. Chergui, Angewandte Chemie International Edition 2009, 48, 7184-7187.

[54] N. Huse, H. Cho, K. Hong, L. Jamula, F. M. F. D. Groot, T. K. Kim, J. K. McCusker, R. W. Schoenlein, F. M. F. de Groot, The Journal of Physical Chemistry Letters 2011, 2, 880-884. 